\title{
ANALISIS KAPABILITAS PROSES UNTUK PENGENDALIAN KUALITAS PRODUK PEMBATAS BUKU INDUSTRI RUMAHAN
}

\author{
*( Diah Ayu Novitasari \\ Fakultas Ekonomi \\ Universitas Islam Lamongan
}

\begin{abstract}
ABSTRAK
Cacat suatu produk merupakan salah satu ukuran kualitas produk yang dapat diamati secara langsung oleh konsumen. Konsumen tidak akan menerima produk yang dibeli jika terdapat kecacatan dalm produk tersebut. Semakin banyak produk cacat maka kualitas proses semakin rendah. Untuk itu perusahaan harus mampu mengurangi produk yang cacat. Pengawasan yang ketat terhadap proses produksi menjadi suatu hal yang sangat penting untuk mengurangi jumlah produk yang cacat. Usaha yang penting dilakukan adalah dengan melakukan kontrol produk terhadap cacat atau tidaknya suatu barang. Untuk menggambarkan variasi jumlah cacat per unit produk pada suatu produksi dari waktu ke waktu, dapat digunakan salah satu peta kendali atribut yaitu peta c. Pada perhitungan secara manual didapatkan nilai $B K A=16.178$ dan nilai $\quad B K B=-0.578$, namun karena jumlah cacat tidak mungkin kurang dari nol maka ditetapkan nilai $B K B=0$. Karena nilai $C p<1$ maka batas spesifikasi yang ada lebih kecil dari sebaran pengamatan yang dilakukan sehingga proses pembuatan pembatas buku perlu ditingkatkan agar sesuai dengan kualitas yang diinginkan. Sedangkan Cpk $<1$ maka mean proses berada di luar batas spesifikasi yang berarti akurasi rendah.
\end{abstract}

Kata Kunci: Pembatas buku, Peta kendali c, diagram pareto, diagram ishikawa, analisis kapabilitas.

\section{PENDAHULUAN}

Salah satu ukuran kualitas produk adalah cacat dan tidak cacat. Semakin banyak produk cacat maka kualitas proses semakin rendah dan sebaliknya, semakin sedikit produk yang cacat maka semakin tinggi kualitas proses. Untuk itu perusahaan harus mengurangi produk yang cacat atau menciptakan rancangan dengan inovasi baru untuk menghindari kekecewaan konsumen. Pengawasan yang ketat terhadap proses produksi menjadi suatu hal yang sangat penting untuk mengurangi jumlah produk yang cacat. Usaha yang penting dilakukan adalah dengan melakukan kontrol produk terhadap cacat atau tidaknya suatu barang.

Benda yang cacat adalah unit produk yang tidak memenuhi satu atau beberapa spesifikasi untuk produk itu. Tiap satu benda cacat dapat memuat satu atau beberapa jenis cacat. Untuk menggambarkan variasi jumlah cacat per unit produk pada suatu produksi dari waktu ke waktu, dapat digunakan salah satu peta kendali atribut yaitu peta c.

Dalam penelitian ini dibahas penggunaan peta kendali c untuk mengevaluasi proses pembuatan pembatas buku dengan cara mengamati proses pengukuran, pengguntingan dan kebersihan dari bagian-bagian pembatas buku yang meliputi badan, jendela dan ban. Melalui peta c akan diketahui pula apakah proses terkendali secara statistik serta apakah proses pembuatan pembatas buku tersebut kapabel. 


\section{Uji Kerandoman Data}

Uji ini dilakukan dengan cara mengukur kerandoman populasi yang didasarkan atas data hasil pengamatan melalui data sampel (Sugiyono, 2008). Uji ini berdasarkan adanya suatu runtun (run test), yaitu barisan abjad-abjad atau tanda-tanda yang identik yang diikuti dengan satu abjad atau satu tanda yang berbeda. Uji run ini akan mengkonversi banyaknya run ke dalam statistik $Z$ dengan pendekatan distribusi normal (Andi, 1998).

Hipotesis :

$\mathrm{H}_{0}$ : Data pengamatan telah diambil

secara acak dari suatu populasi

$\mathrm{H}_{1}$ : Data pengamatan tidak diambil secara tidak acak dari suatu populasi Statistik Uji yang digunakan adalah :

$$
Z=\frac{\text { observed }- \text { expected }}{\sqrt{\text { variance }}} \text { ) }
$$

Dimana :

observed $=$ banyaknya runs dalam sampel

expected $=1+\frac{2 * A * B}{N}$

var iance $=\frac{2 * A * B(2 * A * B-N)}{N^{2}(N-1)}$

Keterangan:

$\mathrm{A}=$ jumlah observasi diatas $\mathrm{k}$.

$\mathrm{B}=$ jumlah observasi di bawah atau sama

dengan $\mathrm{k}$.

$\mathrm{N}=$ jumlah observasi.

$\mathrm{K}=$ nilai rata-rata.

Keputusan :

Tolak $\mathrm{H}_{0}$ jika $\mathrm{P}$-value $<$ nilai $\alpha(0.05)$.

\section{Peta C}

Peta pengendali atribut c merupakan peta control yang digunakan jika karakteristik kualitas bersifat atribut yaitu karakteristik kualitas yang tidak bisa diukur secara numerik melainkan hanya dapat membedakan seperti cacat atau tidak cacat (Grant, 1991). Peta pengendali atribut terdiri dari empat macam peta yaitu peta $\mathrm{p}$, peta $\mathrm{np}$, peta $\mathrm{c}$ dan peta $\mathrm{u}$.

Peta c merupakan salah satu peta control atribut selain peta $\mathrm{p}, \mathrm{np}$, dan $\mathrm{u}$. pada peta $\mathrm{c}$ digambarkan variasi jumlah cacat per unit produk dari suatu proses produksi dari waktu ke waktu. Dalam kasus ini setiap produk dianggap sebagai satu unit dan didalamnya memuat cacat, jumlahnya bias lebih dari satu. Untuk menetapkan batas kendali, digunakan prinsip distribusi poisson karena jumlah kesempatan untuk terjadinya cacat dalam setiap unit tidak terhingga, sementara peluang (probabilitas) terjadinya cacat dalam setiap unit mendekati nol. Hal ini disebabkan karena dalam proses produksi selalu diusahakan agar tidak terjadi cacat dengan cara mengkondisikan faktorfaktor $4 \mathrm{M}+1 \mathrm{E}$ ( Manusia, metode, mesin, material dan lingkungan).

Batas kendali peta $\mathrm{c}$ adalah sebagai berikut:

$$
\begin{aligned}
& B K A=\bar{c}+3 \sqrt{\bar{c}}>0 \\
& B K B=\bar{c}-3 \sqrt{\bar{c}}
\end{aligned}
$$

Peta pengendali untuk ketidaksesuaian kadang-kadang dibentuk dengan menggunakan pemeriksaan produk $100 \%$, sehingga menyebabkan banyak unit dalam sampel tidak konstan. Dari peta kontrol dapat dievaluasi mengenai kondisi proses yaitu proses dalam keadaan terkendali apabila semua titik pengamatan berada diantara batas kendali dan menyebar secara secara random (acak). Proses dapat dikatakan terkendali jika:

1. Tidak ada titik yang berada diluar batas kendali (terkendali secara statistik).

2. Nilai $\mathrm{Cp}>1$

3. Nilai $\mathrm{Cpk}>1$

\section{Diagram Ishikawa}

Diagram Ishikawa adalah diagram yang menyajikan suatu permasalahan 
secara lengkap untuk menyatakan hubungan antara masalah atau akibat dengan faktor-faktor yang menyebabkan terjadinya suatu masalah, sehingga memungkinkan dilakukan suatu analisis yang lebih terperinci dalam menemukan sebab-sebab timbulnya suatu masalah, ketidaksesuaian, dan kesenjangan yang ada. Kualitas yang akan diperbaiki dan dikendalikan disebut karakteristik kualitas dan komposisi yang menyebabkan penyebaran atau sumber masalah disebut dengan faktor.

Kegunaan Diagram Ishikawa adalah sebagai berikut :

1. Mengidentifikasi sebab-sebab terjadinya masalah dan akibatnya dalam bentuk nyata

2. Membantu mengantisipasi timbulnya suatu masalah

3. Mengidentifikasi penyebab dari suatu masalah sehingga dapat diketahui sumber terjadinya suatu masalah

4. Mengantisipasi suatu masalah sehingga mendapatkan kontrol yang baik

Pengertian lain dari diagram Ishikawa yaitu diagram yang menyerupai tulang ikan yang dapat memberitahu suatu masalah secara lengkap dengan rumus : $4 \mathrm{M}+\mathrm{E}$ dimana $4 \mathrm{M}$ adalah

1. Mesin

2. Manusia

3. Metode

4. Material

Sedangkan E adalah Environment atau diartikan Lingkungan (Montgomery, 2005).

\section{Kapabilitas Proses}

Kapabilitas proses merupakan suatu analisis variabilitas relatif terhadap persyaratan atau spesifikasi produk serta untuk membantu pengembangan produksi dalam menghilangkan atau mengurangi banyak variabilitas yang terjadi. Kapabilitas proses ini merupakan suatu ukuran kinerja kritis yang menunjukkan proses mampu menghasilkan sesuai dengan spesifikasi produk yang diterapkan oleh manajemen berdasarkan kebutuhan dan ekspektasi pelanggan (Gaspersz, 2002).

Ada dua cara memikirkan variabilitas ini

1. Variabilitas yang menjadi sifat atau alami pada waktu tertentu yakni variabilitas 'seketika'

2. Variabilitas meliputi waktu

Diantara penggunaan data yang utama dari analisis kemampuan proses adalah sebagai berikut :

1. Memperkirakan seberapa baik proses akan memenuhi toleransi

2. Membantu pengembang atau perancang produk dalam memilih atau mengubah proses

3. Membantu dalam pembentukan interval untuk pengendalian interval antara pengambilan sampel

4. Menetapkan persyaratan penampilan bagi alat baru

5. Memilih diantara penjual yang bersaing

6. Mengurangi variabilitas dalam proses produksi

Indikator kapabilitas proses adalah :

1) Indeks $\mathrm{Cp}$

a. 2 spesifikasi

$$
\mathrm{Cp}=(\mathrm{BSA}-\mathrm{BSB}) / 6 \sigma
$$

b. 1 spesifikasi $\mathrm{Cp}=\frac{B S A-\bar{c}}{3 \sigma}$ atau

$$
\frac{\bar{c}-B S B}{3 \sigma}
$$

Menurut Breyfogle (2006), nilai standar sigma untuk $\mathrm{Cp}$ dapat dikelompokkan dalam 3 kategori :

1. $C_{P}=2$ maka proses sudah sesuai harapan

2. $\mathrm{C}_{\mathrm{P}}<2$ maka proses berada diluar batas spesifikasi

3. $\mathrm{C}_{\mathrm{P}}>2$ maka proses sudah sesuai spesifikasi

2) Indeks Cpk 
Nilai standar sigma untuk Cpk adalah sebagai berikut :

1. Cpk $<0$, menunjukkan rata-rata proses diluar batas spesfikasi, berarti akurasi rendah.

2. $0<\mathrm{Cpk}<1.5$, menunjukkan akurasi dan presisi masih rendah jika nilai $\mathrm{Cpk}<1.5$, tetapi jika nilai $\mathrm{Cp}>1.5$, maka presisi tinggi tetapi akurasi rendah.

3. $\mathrm{Cpk}>1.5$, jika diikuti nilai $\mathrm{Cp}>$ 1, maka proses kapabel dan akurasi serta presisi tinggi. Tetapi jika nilai $\mathrm{Cp}<1$, berarti tingkat akurasi tinggi dan presisi rendah.

\section{METODOLOGI PENELITIAN}

Sumber data yang akan dijadikan sebagai bahan analisis dalam penelitian ini adalah jumlah pembatas buku yang cacat diantara 30 pembatas buku yang dibagi kedalam 10 subgroup dengan ukuran sampel masing-masing 3. Data diambil dari industri rumah yang membuat pembatas buku.

Langkah-langkah analisis data penelitian ini adalah sebagai berikut:

1. Melakukan uji kerandoman data jumlah cacat pada pembatas buku.

2. Membuat peta kendali c berdasarkan jumlah cacat pada pembatas buku.

3. Membuat diagram pareto berdasarkan jenis cacat pada pembatas buku.

4. Membuat diagram ishikawa dari dua jenis kategori cacat terbanyak pada pembatas buku.

5. Menghitung kapabilitas proses pembuatan pembatas buku

\section{HASIL DAN PEMBAHASAN \\ Uji Kerandoman Data}

Hipotesis yang digunakan untuk uji kerandoman data pada jumlah pembatas buku yang cacat adalah sebagai berikut :

$\mathrm{H}_{0}$ : Data pengamatan diambil secara acak dari suatu populasi
$\mathrm{H}_{1}$ : Data pengamatan yang diambil secara tidak acak dari suatu populasi

$\square=0.05$

Statistik Uji : Run Test

Daerah penolakan : Tolak Ho jika Asymp-Sig $<\square$

Tabel 1. Uji Kerandoman dari jumlah cacat

\begin{tabular}{|c|c|}
\hline Runs above and below $\mathrm{K}$ & 2,6 \\
\hline $\begin{array}{l}\text { The Observed number of } \\
\text { runs }\end{array}$ & 18 \\
\hline $\begin{array}{l}\text { The Expected number of } \\
\text { runs }\end{array}$ & 15,9333 \\
\hline Asymp-Sig & 0,440 \\
\hline
\end{tabular}
didapatkan nilai Asymp-Sig ( -value) 0,440 . Karena nilai $p$-value lebih besar jika dibandingkan dengan $\square$ maka terima $\mathrm{H}_{0}$. Sehingga data jumlah cacat pada pembatas buku bersifat random.

\section{Peta kendali c}

Setelah diketahui bahwa data memenuhi asumsi random dan distribusi poisson, maka dapat dilanjutkan dengan pembuatan peta kendali c sebagai berikut:

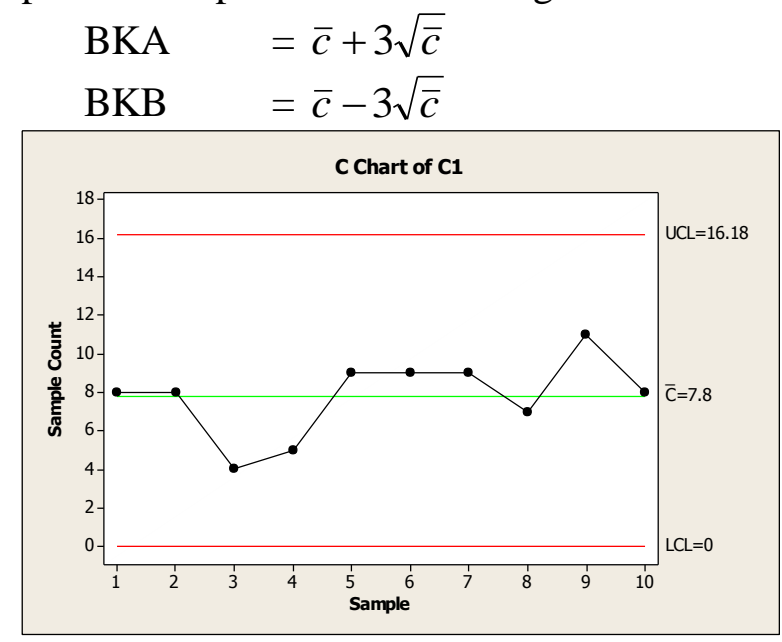

Gambar 1. Peta C

Berdasarkan gambar 1 dapat ditarik kesimpulan bahwa proses pembuatan pembatas buku telah terkendali secara statistik, karena semua titik pengamatan berada didalam batas kendali. Perhitungan manualnya sebagai berikut : 
$\mathrm{BKA}=\bar{c}+3 \sqrt{\bar{c}}=7.8+3 *(2.793)=$ 16.178

$\mathrm{BKB}=\bar{c}-3 \sqrt{\bar{c}}=7.8+3 *(2.793)=-$ 0.578

Pada perhitungan secara manual didapatkan nilai $\mathrm{BKA}=16.178$ dan nilai $\mathrm{BKB}=-0.578$, namun karena jumlah cacat tidak mungkin kurang dari nol maka ditetapkan nilai $\mathrm{BKB}=0$.

\subsection{Diagram Ishikawa untuk jenis cacat dalam pengguntingan}

Diagram ini digunakan untuk mengetahui faktor-faktor yang menyebabkan tingginya jumlah cacat pada jenis cacat penguntingan ban dan pengguntingan badan.

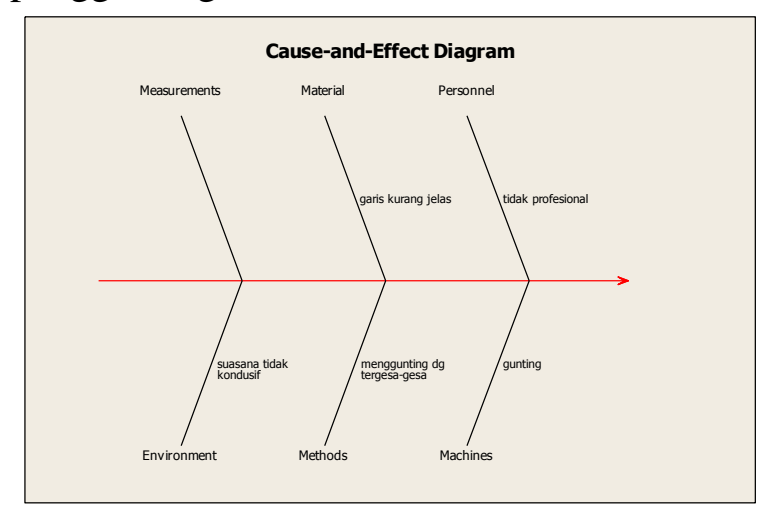

Gambar 2. Diagram Ishikawa pengguntingan ban

Diagram ishikawa di atas menunjukkan bahwa faktor-faktor yang menyebabkan tingginya jumlah cacat pada jenis cacat penguntingan ban

1. Manusia :Tidak profesional.

2. Mesin :Gunting yang digunakan tidak berkualitas

3. Metode :Menggunting dengan terges-gesa

4. Material : Garis kurang jelas

5. Lingkungan : Suasana kurang kondusif

Diagram Ishikawa untuk jenis cacat dalam pengguntingan badan

Diagram ini digunakan untuk mengetahui faktor-faktor yang menyebabkan tingginya jumlah cacat pada jenis cacat penguntingan ban dan pengguntingan badan.

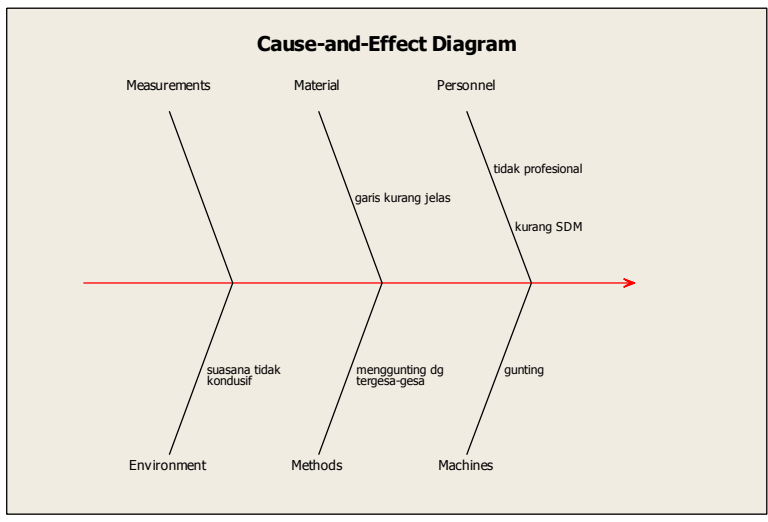

Gambar 3. Diagram Ishikawa pengguntingan badan

Diagram ishikawa di atas menunjukkan bahwa faktor-faktor yang menyebabkan tingginya jumlah cacat pada jenis cacat pengguntingan badan.

1. Manusia/Operator :Tidak professional dan kurang SDM.

2. Alat/Mesin :Gunting yang digunakan tidak berkualitas

3. Metode :Menggunting dengan terges-gesa

4. Material : Garis kurang jelas

5. Lingkungan :Suasana kurang kondusif

\section{Kapabilitas Proses}

Analisis Kapabilitas Proses digunakan untuk mengetahui seberapa baik proses pembuatan pembatas buku berupa mobil. Batas spesifikasi atas yang telah ditentukan adalah 4

Kapabilitas proses tidak cukup hanya dengan mengetahui bahwa proses dalam keadaan terkendali, melainkan ada dua criteria yang lain yang juga harus dipenuhi, yaitu memenuhi batas-batas spesifikasi serta memiliki tingkat presisi dan akurasi yang tinggi. 


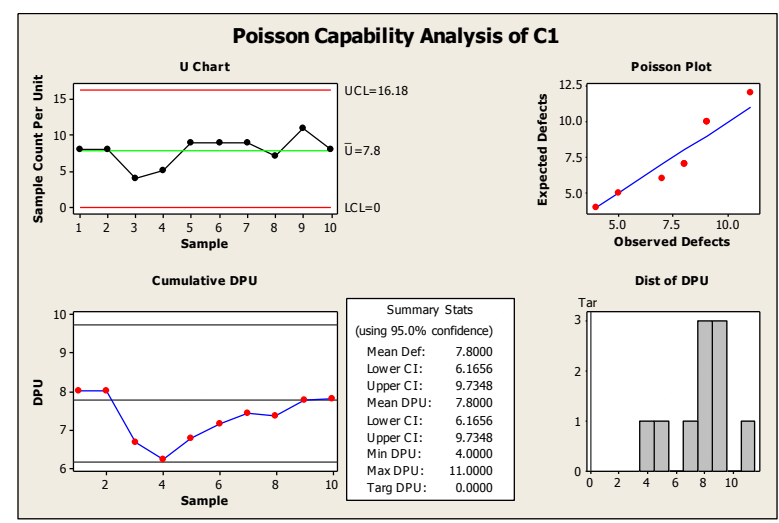

Gambar 4. Diagram Kapabilitas proses Perhitungan manualnya sebagai berikut :

$$
\begin{aligned}
& \text { Dengan } \sigma=\sqrt{\bar{c}}=2.793 \\
& C p=\frac{B S A-B S B}{6 \sigma}=\frac{4-0}{6(2.793)}=0.23869 \\
& C p(A)=\frac{B S A-\bar{c}}{3 \sigma}=\frac{4-7.8}{3(2.793)}=-0.4535 \\
& C p(B)=\frac{\bar{c}-B S B}{3 \sigma}=\frac{7.8-0}{3(2.793)}=0.93 \\
& C_{p k}=\min \left\{C_{p}(A)_{3} C_{p} \$(B)\right\} \\
& =-0.4535
\end{aligned}
$$

Karena nilai $\mathrm{Cp}<1$ maka batas spesifikasi yang ada lebih kecil dari sebaran pengamatan yang dilakukan sehingga proses pembuatan pembatas buku perlu ditingkatkan agar sesuai dengan kualitas yang diinginkan. Sedangkan Cpk <1 maka mean proses berada di luar batas spesifikasi yang berarti akurasi rendah.

\section{KESIMPULAN}

Berdasarkan hasil analisis dan pembahasan, maka dapat disimpulkan bahwa data jumlah cacat produk pembatas buku berasal dari populasi yang acak dan berdistribusi Poisson. Peta Control atribut $\mathrm{C}$ menunjukkan bahwa proses pembuatan pembatas buku berada a, Bandung. dalam keadaan terkendali. Berdasarkan diagram pareto didaptkan kesimpulan bahwa jumlah cacat terbanyak terletak pada pengguntingan ban dan pengguntingan badan. Diagram Ishikawa menunjukan faktor-faktor yang menyebabkan terjadinya cacat adalah pekerja yang kurang professional, alat gunting yang kurang berkualitas, lingkungan produksi yang tidak kondusif, material dengan garis yang kurang jelas, dan metode yang digunakan saat pembuatan pembatas buku yang tergesagesa. Semua hal diatas menyebabkan proses pembuatan pembatas buku tidak kapabel dikarenakan Cp dan Cpk kurang dari 1.

\section{DAFTAR PUSTAKA}

[1] Andi, 1998. Panduan Lengkap SPSS 6.0 for windows, Wahana Komputer, Bandung.

[2] Breyfogle, F.W, 2003. Implementation Six Sigma, Smart Solutions Using Statistical Methods, John Willey \& Sons, Inc. New Jersey.

[3] Gaspersz, V., (2002), Pedoman Implementasi Program Six Sigma Terintegrasi dengan ISO 9001:2000, MBNQA, dan HACCP, PT. Gramedia Pustaka Utama, Jakarta.

[4] Grant, (1991), Pengendalian Mutu Statistik, Erlangga, Jakarta.

[5] Montgomery, Douglas C, (2005), Introduction to Statistical Quality Control Fifth Edition. John Wiley \&Sons, Inc, New York.

[6] Sugiyono,(2008), Statistika Nonparametris untuk penelitian, $\mathrm{CV}$ Alfabet 